\title{
Full-length Ebola glycoprotein accumulates in the endoplasmic reticulum
}

Suchita Bhattacharyya ${ }^{1,2}$, Thomas J Hope ${ }^{1 *}$

\begin{abstract}
The Filoviridae family comprises of Ebola and Marburg viruses, which are known to cause lethal hemorrhagic fever. However, there is no effective anti-viral therapy or licensed vaccines currently available for these human pathogens. The envelope glycoprotein (GP) of Ebola virus, which mediates entry into target cells, is cytotoxic and this effect maps to a highly glycosylated mucin-like region in the surface subunit of GP (GP1). However, the mechanism underlying this cytotoxic property of GP is unknown. To gain insight into the basis of this GP-induced cytotoxicity, HEK293T cells were transiently transfected with full-length and mucin-deleted (Amucin) Ebola GP plasmids and GP localization was examined relative to the nucleus, endoplasmic reticulum (ER), Golgi, early and late endosomes using deconvolution fluorescent microscopy. Full-length Ebola GP was observed to accumulate in the ER. In contrast, GPAmucin was uniformly expressed throughout the cell and did not localize in the ER. The Ebola major matrix protein VP40 was also co-expressed with GP to investigate its influence on GP localization. GP and VP40 coexpression did not alter GP localization to the ER. Also, when VP40 was co-expressed with the nucleoprotein (NP), it localized to the plasma membrane while NP accumulated in distinct cytoplasmic structures lined with vimentin. These latter structures are consistent with aggresomes and may serve as assembly sites for filoviral nucleocapsids. Collectively, these data suggest that full-length GP, but not GP $\Delta$ mucin, accumulates in the ER in close proximity to the nuclear membrane, which may underscore its cytotoxic property.
\end{abstract}

\section{Findings}

Ebola GP is the only viral protein expressed on the virus surface and mediates entry into target cells [1], [2]. However, several studies report that GP expression also causes cell rounding and cytotoxicity, although the underlying mechanism remains unknown. For instance, expression of Ebola GP but not Marburg GP is reported to cause cell detachment without death [3]. Additionally, Ebola GP from Zaire, Sudan and Ivory Coast subtypes are shown to cause cell rounding and detachment ascribed to down-regulation of MHC class I and cell surface adhesion proteins [4], [5]. Interestingly, Ebola GP from the Reston subtype, believed to be non-pathogenic to humans, had a less severe cell rounding effect [4]. GP is also believed to be a key determinant of viral pathogenesis and virus-like particles (VLPs) containing GP are shown to activate human endothelial cells and

\footnotetext{
* Correspondence: thope@northwestern.edu

'Department of Cell and Molecular Biology, Feinberg School of Medicine, Northwestern University, 303 East Chicago Avenue, Chicago, Illinois 60611, USA

Full list of author information is available at the end of the article
}

macrophages [6], [7]. Importantly, the mucin-like region in GP1 is specifically shown to induce cytotoxicity when GP is expressed at similar levels to that seen during Ebola virus infection. Additionally, the other virus proteins tested were not cytotoxic [8]. Collectively, these reports indicate that Ebola GP imparts cell rounding and cytotoxicity in addition to facilitating viral entry.

However, separate work reports that Ebola Zaire GP is not cytotoxic when expressed in isolation at similar levels to that seen during early virus infection [9]. Another study shows that GP is not detected in cells infected with Ebola Zaire virus [10]. This failure to detect GP during infection may arise as GP is released from the infected cells either as soluble glycoprotein (sGP) or a soluble form of GP1 [11]. As full-length GP but not sGP is shown to cause cytotoxicity [12], this suggests that the release of sGP during Ebola virus infection could be a mechanism used by the virus to prevent cytotoxicity and replicate and spread throughout the body. Moreover, this release of sGP may also explain why Ebola Zaire GP expressed at levels similar to early infection is not cytotoxic [9].

\section{Biomed Central}


Previous studies suggest that Ebola GP is incorporated into VLPs along with the viral VP40 and NP proteins when co-expressed in cells [13], [14], [15]. VP40 is the major matrix protein of Ebola and can drive the formation of filamentous VLPs that resemble wildtype Ebola virus morphology [13]. VP40 plays an important role in viral replication, assembly and budding [16]. VP40 interacts with cellular factors such as the Nedd4 ubiquitin ligase, Tsg101 that comprises part of the ESCRT-I complex, and Sec24C that is a component of the COPII complex [17], [18], [19]. VP40 also has RNA binding and oligomerization properties [20]. The Ebola NP is the principal component of the ribonucleocapsid, which encloses the RNA [21] and is phosphorylated [22].

As the majority of studies suggest a critical role of Ebola GP in causing cytotoxicity [3], [4], [8], [5], [23], [24], and GP interacts with VP40 and NP to form viral particles [13], [14], [15], we therefore investigated the cellular localization of GP, VP40 and NP when transiently expressed in HEK293T cells. Since Ebola GP induces cell rounding and detachment 24 hours after transfection [8], the cellular localization of Ebola GP was examined here 24 hours after transient transfection to try gain insight into the mechanism of GP cytotoxicity.

To this end, HEK293T cells were transiently transfected for 24 hours using the calcium phosphate transfection method [25] with various plasmids. To compare wildtype GP and GP $\Delta$ mucin localization, $10 \mu \mathrm{g}$ full- length Ebola Zaire GP (pCB6-EbGP) [2] or GP $\Delta$ mucin (pCDNA6-EbGP $\Delta$ mucin-mut $\Delta 1234$ ) [4] were transfected. Their localization relative to cellular ER and Golgi were examined by transfecting $8 \mu \mathrm{g}$ GP or GP $\Delta$ mucin with $2 \mu \mathrm{g}$ pDsRed2-ER or pEYFP-Golgi (Clontech). GP, VP40 and NP localization when expressed in varying combinations were examined by transfecting $5 \mu \mathrm{g}$ eGFP-VP40 [26] and $5 \mu \mathrm{g}$ GP or NP plasmids, or $10 \mu \mathrm{g}$ NP plasmid (pWRG7077-NP) [27] alone. Cells were fixed 24 hours post-transfection and stained. Stains included the Hoechst DNA stain and antibodies targeting nuclear pore complex (NPC) proteins, early or late endosomes. GP was stained with a neutralizing human monoclonal antibody (KZ52) labeled with a Zenon labeling kit (Molecular Probes). Cells were imaged using a DeltaVision microscope with subsequent deconvolution as previously described [28].

Full-length Ebola GP localized in close proximity to the nuclear membrane (Figure 1A). However, NPC staining showed little overlap with GP suggesting GP was not localized on the nuclear membrane. Thus, we hypothesized that GP may localize within the ER. Coexpression of Ebola GP with DsRed2-ER showed that GP had localized within the ER (Figure 1B). Notably, GP was not found within late endosomes (Figure 1B), Golgi or early endosomes (data not shown).

Since full-length GP localized within the ER in close proximity to the nuclear membrane, we then examined
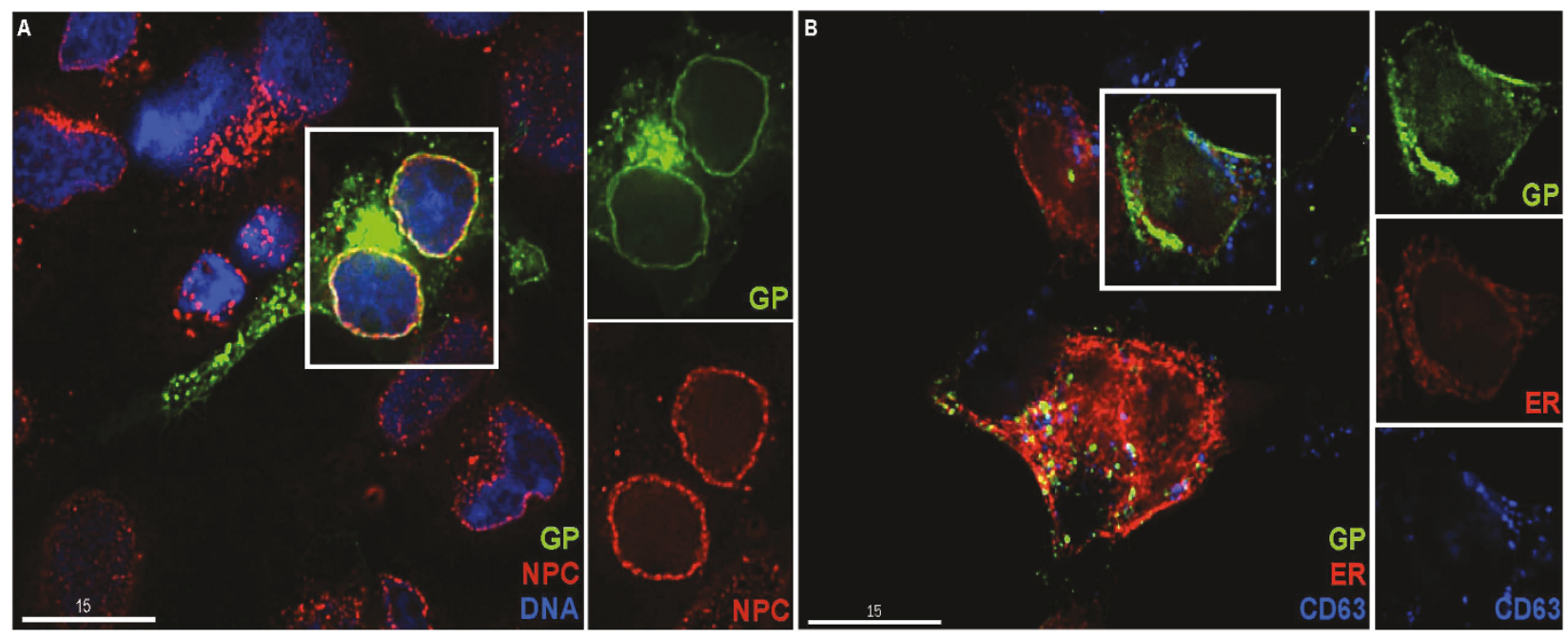

Figure 1 Full-length Ebola GP localizes in the ER in close proximity to the nuclear membrane. A. HEK293T cells were transiently transfected with $10 \mu \mathrm{g}$ GP (pCB6-EbGP) plasmid for 24 hours. Cells were fixed and stained for DNA (blue) using Hoechst, nuclear pore complex (NPC, red) proteins using mouse monoclonal antibody 414 (Covance Research Products), and GP (green) using the neutralizing human monoclonal antibody (KZ52) labeled with a Zenon labeling kit (Molecular Probes). Scale bar represents $15 \mu \mathrm{m}$. Side panels show individual fluorescent channels from the boxed region in the image. B. HEK293T cells were transiently transfected for 24 hours with $8 \mu \mathrm{g} \mathrm{GP}$ and $2 \mu \mathrm{g}$ pDsRed2-ER vector (Clontech) that labels the endoplasmic reticulum (ER, red). Cells were fixed and stained for late endosomes using a mouse monoclonal antibody targeting CD63 (BD Biosciences, blue), in accordance with a previous publication [43]. GP was stained as above (green). Scale bar represents $15 \mu \mathrm{m}$. Side panels show individual fluorescent channels from the boxed region in the image. 
whether GP lacking the mucin-like region and cytotoxic activity [4], [8] also localized in the ER. Strikingly, while GP $\Delta$ mucin was expressed at comparable levels to fulllength GP, it did not accumulate in the ER (Figure 2A). Instead, GP $\Delta$ mucin was uniformly expressed throughout the cell and did not localize within Golgi, early endosomes (Figure 2B), or late endosomes (Figure 2C) either. This dispersed localization suggests that it is diffusely localized in the plasma membrane.

Co-expression of GP and VP40 did not alter the localization of either protein. GP remained in close proximity to the nuclear membrane consistent with an ER localization while VP40 localized near the plasma membrane (Figure 3A), which agrees with previous reports [29], [30], [31]. However, separate studies show that Ebola GP localizes in the plasma membrane of either tissues from experimentally infected non-human primates [10] or HeLa cells 48 hours post-transfection [24]. Additionally, GP is reported to localize within VP40 filamentous structures following GP and VP40 coexpression, suggesting GP interacts with VP40 during morphogenesis [13]. While we observed little overlay between GP and VP40 here, GP must associate with VP40 filaments to produce infectious virions perhaps during a later phase of the viral replication cycle. Therefore at this early 24 hour time-point, it is likely the GP amount associated with the VP40 filamentous structures is limited compared to the total cellular amount of GP, making it difficult to visualize by fluorescence microscopy here.

Ebola NP expressed in isolation accumulated in large cytoplasmic aggregates (Figure 3B). Staining for the intermediate filament protein, vimentin revealed these NP aggregates were lined with vimentin. Aggresomes are perinuclear structures lined with vimentin, which recruit molecular chaperones and proteosomes. They are believed to regulate protein folding and degradation of misfolded proteins [32]. Therefore, the NP association with vimentin here suggests the NP was present in aggresome-like structures. Previous studies using cells infected with Marburg virus report Marburg NP accumulates in structures resembling inclusion bodies in close proximity to the ER [33], [34]. So it is possible that the Ebola NP in these aggresome-like structures could perhaps serve as sites for assembly of filoviral nucleocapsid analogous to African swine fever virus [35] and herpes simplex virus type 2 [36].

VP40 and NP did not colocalize upon co-expression (Figure 3C). VP40 was seen as filamentous structures near the plasma membrane, while NP was localized within distinct cytoplasmic aggresome-like bodies. Actin staining also showed little overlay with either VP40 or NP (Figure $3 \mathrm{D})$, correlating with the report that actin incorporates into VLPs containing both GP and VP40, but not VP40
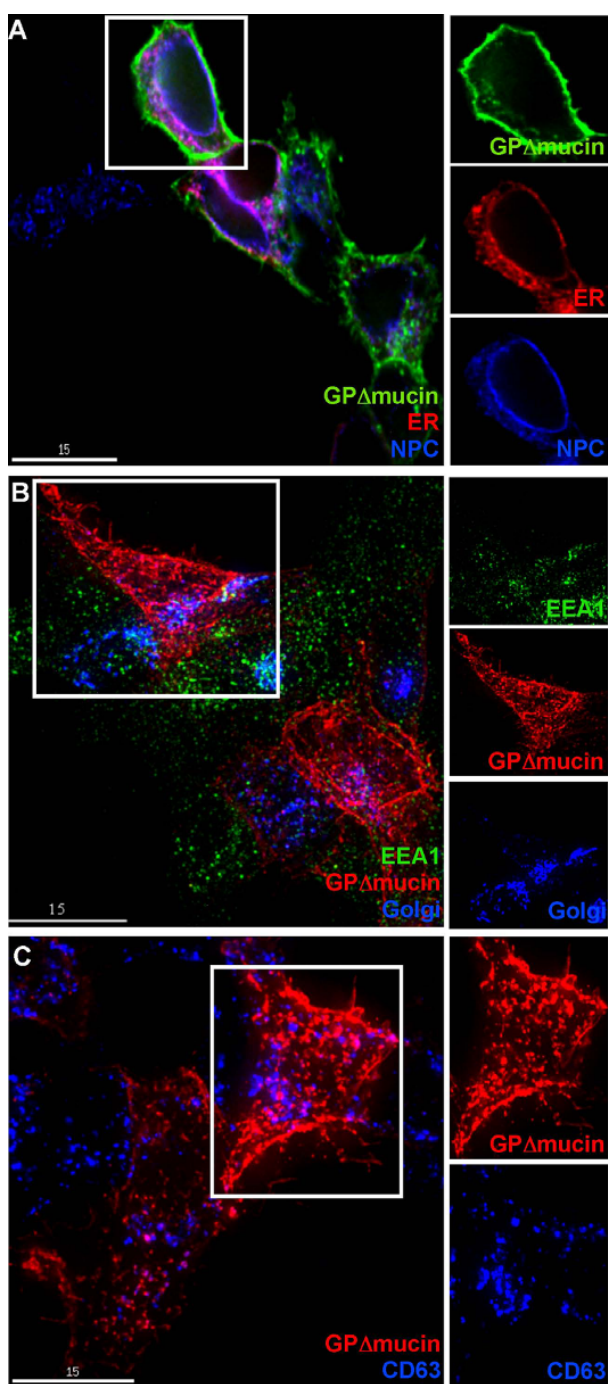

Figure 2 Ebola GP lacking the mucin-like region does not accumulate in the ER. A. HEK293T cells were transiently transfected for 24 hours with $8 \mu \mathrm{g}$ GPAmucin (pCDNA6EbGP $\Delta$ mucin-mut $\triangle 1234)$ and $2 \mu \mathrm{g}$ pDsRed2-ER vector (Clontech) that labels the endoplasmic reticulum (ER, red). Cells were fixed and stained for NPC proteins (blue) using mouse monoclonal antibody 414 (Covance Research Products) and GP $\triangle$ mucin (green) using the KZ52 neutralizing human monoclonal antibody labeled with a Zenon labeling kit (Molecular Probes). Scale bar represents $15 \mu \mathrm{m}$. Side panels show individual fluorescent channels from the boxed region in the image. B. HEK293T cells were transiently transfected for 24 hours with $8 \mu \mathrm{g}$ GPAmucin and $2 \mu \mathrm{g}$ pEYFP-Golgi vector (Clontech) that labels the trans-medial region of the Golgi apparatus (blue). Cells were fixed and stained for early endosomes using a mouse monoclonal antibody against EEA1 (BD Biosciences, green) and for GPAmucin as above (red). Scale bar represents $15 \mu \mathrm{m}$. Side panels show individual fluorescent channels from the boxed region in the image. C. HEK293T cells were transiently transfected with 10 $\mu \mathrm{g}$ GP $\triangle$ mucin for 24 hours. Cells were fixed and stained for late endosomes using a mouse monoclonal antibody targeting CD63 (BD Biosciences, blue) and for GPAmucin as above (red). Scale bar represents $15 \mu \mathrm{m}$. Side panels show individual fluorescent channels from the boxed region in the image. 

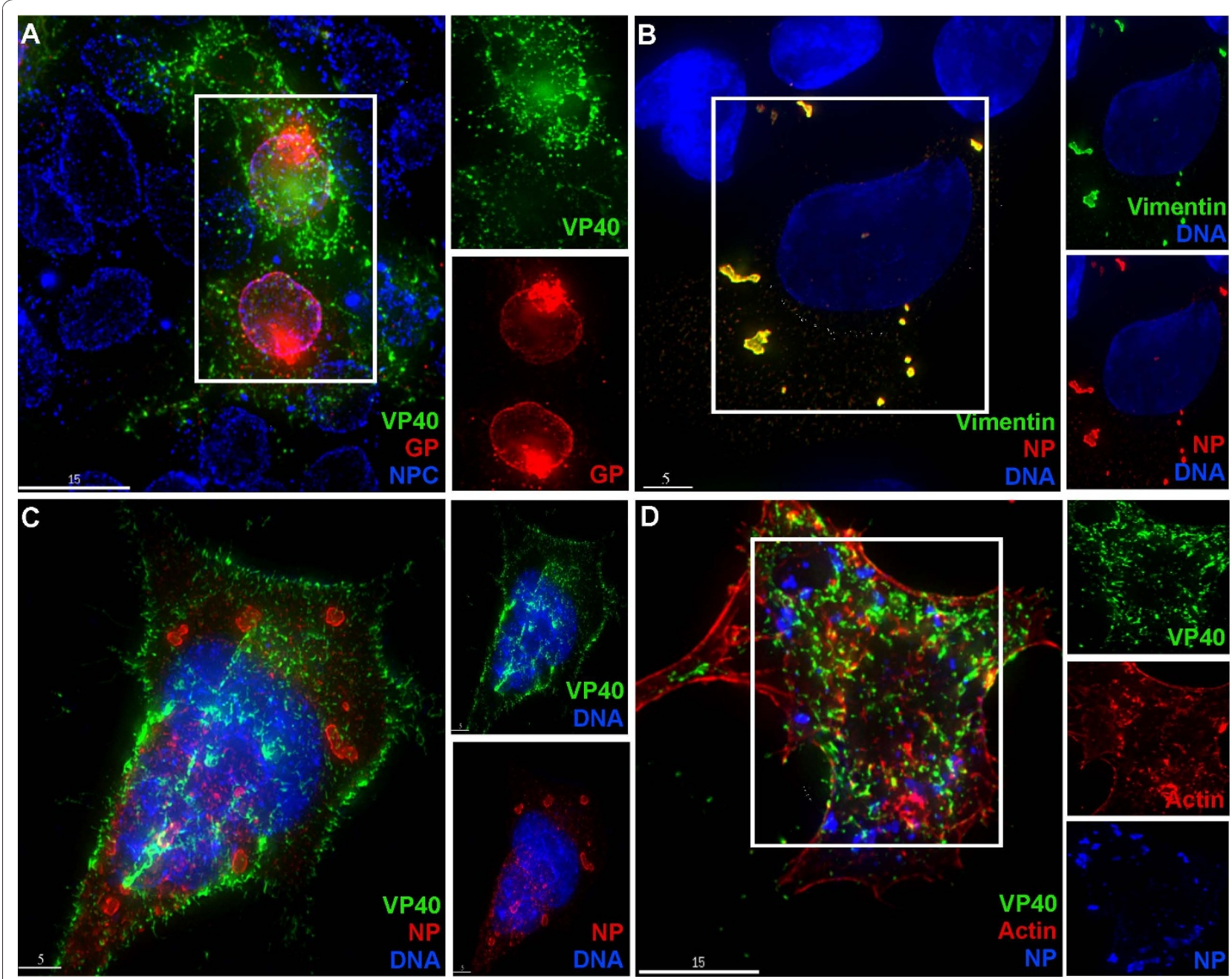

Figure 3 Co-expression of Ebola GP, VP40 and NP in HEK293T cells does not alter localization of individual proteins. A. HEK293T cells were co-transfected with $5 \mu \mathrm{g}$ Ebola GP and $5 \mu \mathrm{g}$ eGFP-VP40 plasmids for 24 hours. Cells were fixed and stained for NPC proteins using mouse monoclonal antibody 414 (Covance Research Products, blue) and GP (red) using KZ52 neutralizing human monoclonal antibody labeled with a Zenon labeling kit (Molecular Probes). Green represents VP40. Scale bar represents $15 \mu \mathrm{m}$. Upper and lower side panels show VP40 and GP fluorescence respectively, from the boxed region in the image. B. HEK293T cells were transfected with $10 \mu \mathrm{g}$ Ebola NP plasmid for 24 hours. Cells were fixed and stained for DNA using Hoechst (blue), NP using a mouse monoclonal antibody targeting NP (red) and vimentin using a mouse monoclonal antibody targeting vimentin (green). Scale bar represents $5 \mu \mathrm{m}$. Upper and lower side panels show the vimentin and DNA fluorescence and the NP and DNA fluorescence respectively, from the boxed region in the image. C. HEK293T cells were co-transfected with 5 $\mu \mathrm{g}$ Ebola NP and $5 \mu \mathrm{g}$ eGFP-VP40 plasmids for 24 hours. Cells were fixed and stained for NP using a mouse monoclonal antibody targeting NP (red) and DNA using Hoechst (blue). Green represents VP40. Scale bar represents $5 \mu \mathrm{m}$. Upper and lower side panels show the VP40 and DNA fluorescence and the NP and DNA fluorescence respectively. D. HEK293T cells were co-transfected with $5 \mu \mathrm{g}$ Ebola NP and $5 \mu \mathrm{g}$ eGFP-VP40 plasmids for 24 hours. Cells were fixed and stained for NP using a mouse monoclonal antibody targeting NP (blue) and filamentous actin using Texas Red Phalloidin (Invitrogen, red). Green represents VP40. Scale bar represents $15 \mu \mathrm{m}$. Side panels show the individual fluorescent channels from the boxed region in the image.

alone [37]. While we did not detect NP in the VP40 filamentous structures here, previous studies suggest that NP interacts directly with VP40, and is present in VP40-containing VLPs when VP40 and NP are co-expressed [14], [15]. Thus, perhaps NP is recruited to VP40-containing VLPs at a later stage during filament formation than the 24 hours experiment here, or another viral protein is required for VP40 and NP interaction.
As filoviral replication takes place in the cytoplasm [38], it is intriguing that full-length GP but not GP $\Delta \mathrm{mu}$ cin, accumulates in the ER in close proximity to the nuclear membrane after 24 hours transient expression in cells. This suggests that full-length GP localization in the ER could play a role in its cytotoxic and cell rounding properties because the mucin-like region of GP is reported to cause cytotoxicity [4], [8]. 
How accumulation of GP in the ER might induce cytotoxic effects remains to be defined. The GP mucin-like region activates the $\mathrm{NF} \kappa \mathrm{B}$ signaling pathway [39] and also downregulates activation of the MAPK effector ERK2, which is linked to GP induced cytotoxicity [40]. Recently, the Classical Swine Fever virus NS2 protein is reported to localize to the ER and cause ER stress and $\mathrm{NF} \kappa \mathrm{B}$ activation [41]. Similarly, the SARS coronavirus 3a protein causes ER stress and activates the PERK pathway leading to unfolded protein response (UPR) [42]. Therefore, Ebola GP accumulation in the ER may interfere with protein synthesis, folding and transport thereby activating UPR to cause ER stress. Understanding the exact mechanism of GP accumulation in the ER and its correlation to cytotoxicity may be useful in designing inhibitors to block this cytotoxic effect during Ebola virus infection of patients and/or potentially reduce the severe pathogenic effects these patients experience.

\section{List of abbreviations}

EbGP: Ebola virus glycoprotein; ER: endoplasmic reticulum; ERK2: mitogen responsive extracellular regulated kinase 2; GP1: surface subunit of GP: GP $\triangle$ mucin: GP with the mucin-like region of GP1 deleted; MAPK: mitogen activated protein kinase; NP: nucleoprotein; NPC: nuclear pore complex PERK: PRKR-like ER kinase; sGP: soluble glycoprotein; UPR: unfolded protein response; VLP: virus-like particle.

\section{Acknowledgements}

We are grateful to Drs. M. Javad Aman (USAMRIIID) for providing the pWRG7077 Ebola NP plasmid and the mouse monoclonal antibody against NP, Paul Bates (University of Pennsylvania) for the full-length pCB6-EbGP Ebola GP (Zaire) and GPAmucin (pCDNA6-EbGPAmucin-mut 1234 ) plasmids, Paul Bieniasz (Aaron Diamond AIDS Research Center) for the eGFP-VP40 plasmid, Dennis Burton (The Scripps Research Institute) for the KZ52 neutralizing human monoclonal antibody against Ebola GP and Robert Goldman (Northwestern University) for the mouse monoclonal antibody against vimentin. We also thank Dr. Jenny L. Anderson (Burnet Institute) for critically reading the manuscript. This work was supported by the National Institutes of Health (NIH) grant R21 Al054495 to TJH. TJH is an Elizabeth Glaser Scientist.

\section{Author details}

'Department of Cell and Molecular Biology, Feinberg School of Medicine, Northwestern University, 303 East Chicago Avenue, Chicago, Illinois 60611, USA. ${ }^{2}$ Current Address: Nomis Center for Immunobiology and Microbial Pathogenesis, The Salk Institute for Biological Studies, 10010 North Torrey Pines Road, La Jolla, California 92037, USA.

\section{Authors' contributions}

SB and TJH conceived and designed the study, SB performed the experiments, and $S B$ and TJH interpreted the results and wrote the manuscript. All authors read and approved the final manuscript.

\section{Competing interests}

The authors declare that they have no competing interests.

Received: 9 September 2010 Accepted: 12 January 2011

Published: 12 January 2011

\section{References}

1. Takada A, Robison C, Goto H, Sanchez A, Murti KG, Whitt MA, Kawaoka Y: A system for functional analysis of Ebola virus glycoprotein. Proc Natl Acad Sci USA 1997, 94:14764-14769.
2. Wool-Lewis RJ, Bates P: Characterization of Ebola virus entry by using pseudotyped viruses: identification of receptor-deficient cell lines. J Virol 1998, 72:3155-3160

3. Chan SY, Ma MC, Goldsmith MA: Differential induction of cellular detachment by envelope glycoproteins of Marburg and Ebola (Zaire) viruses. J Gen Virol 2000, 81:2155-2159.

4. Simmons G, Wool-Lewis RJ, Baribaud F, Netter RC, Bates P: Ebola virus glycoproteins induce global surface protein down-modulation and loss of cell adherence. J Virol 2002, 76:2518-2528.

5. Takada A, Watanabe S, Ito H, Okazaki K, Kida H, Kawaoka Y: Downregulation of beta1 integrins by Ebola virus glycoprotein: implication for virus entry. Virology 2000, 278:20-26.

6. Wahl-Jensen VM, Afanasieva TA, Seebach J, Stroher U, Feldmann $H_{\text {, }}$ Schnittler HJ: Effects of Ebola virus glycoproteins on endothelial cell activation and barrier function. J Virol 2005, 79:10442-10450.

7 Wahl-Jensen V, Kurz SK, Hazelton PR, Schnittler HJ, Stroher U, Burton DR, Feldmann $\mathrm{H}$ : Role of Ebola virus secreted glycoproteins and virus-like particles in activation of human macrophages. J Virol 2005, 79:2413-2419.

8. Yang ZY, Duckers HJ, Sullivan NJ, Sanchez A, Nabel EG, Nabel GJ: Identification of the Ebola virus glycoprotein as the main viral determinant of vascular cell cytotoxicity and injury. Nat Med 2000, 6:886-889.

9. Alazard-Dany N, Volchkova V, Reynard O, Carbonnelle C, Dolnik O, Ottmann M, Khromykh A, Volchkov VE: Ebola virus glycoprotein GP is not cytotoxic when expressed constitutively at a moderate level. J Gen Virol 2006, 87:1247-1257.

10. Steele K, Crise B, Kuehne A, Kell W: Ebola virus glycoprotein demonstrates differential cellular localization in infected cell types of nonhuman primates and guinea pigs. Arch Pathol Lab Med 2001, 125:625-630.

11. Volchkov VE, Volchkova VA, Slenczka W, Klenk HD, Feldmann H: Release of viral glycoproteins during Ebola virus infection. Virology 1998, 245:110-119.

12. Volchkov VE, Volchkova VA, Muhlberger E, Kolesnikova LV, Weik M, Dolnik O, Klenk HD: Recovery of infectious Ebola virus from complementary DNA: RNA editing of the GP gene and viral cytotoxicity. Science 2001, 291:1965-1969.

13. Noda T, Sagara H, Suzuki E, Takada A, Kida H, Kawaoka Y: Ebola virus VP40 drives the formation of virus-like filamentous particles along with GP. $J$ Virol 2002, 76:4855-4865.

14. Licata JM, Johnson RF, Han Z, Harty RN: Contribution of ebola virus glycoprotein, nucleoprotein, and VP24 to budding of VP40 virus-like particles. J Virol 2004, 78:7344-7351

15. Johnson RF, Bell P, Harty RN: Effect of Ebola virus proteins GP, NP and VP35 on VP40 VLP morphology. Virol J 2006, 3:31.

16. Feldmann $H$, Klenk HD, Sanchez A: Molecular biology and evolution of filoviruses. Arch Virol Suppl 1993, 7:81-100.

17. Yasuda J, Nakao M, Kawaoka Y, Shida H: Nedd4 regulates egress of Ebola virus-like particles from host cells. J Virol 2003, 77:9987-9992.

18. Martin-Serrano J, Zang T, Bieniasz PD: HIV-1 and Ebola virus encode small peptide motifs that recruit Tsg101 to sites of particle assembly to facilitate egress. Nat Med 2001, 7:1313-1319.

19. Yamayoshi S, Noda T, Ebihara H, Goto H, Morikawa Y, Lukashevich IS, Neumann G, Feldmann H, Kawaoka Y: Ebola virus matrix protein VP40 uses the COPII transport system for its intracellular transport. Cell Host Microbe 2008, 3:168-177.

20. Hoenen T, Volchkov V, Kolesnikova L, Mittler E, Timmins J, Ottmann M, Reynard O, Becker S, Weissenhorn W: VP40 octamers are essential for Ebola virus replication. J Virol 2005, 79:1898-1905.

21. Sanchez A, Kiley MP, Holloway BP, McCormick JB, Auperin DD: The nucleoprotein gene of Ebola virus: cloning, sequencing, and in vitro expression. Virology 1989, 170:81-91.

22. Elliott $L H$, Kiley MP, McCormick JB: Descriptive analysis of Ebola virus proteins. Virology 1985, 147:169-176.

23. Sullivan NJ, Peterson M, Yang ZY, Kong WP, Duckers H, Nabel E, Nabel GJ: Ebola virus glycoprotein toxicity is mediated by a dynamin-dependent protein-trafficking pathway. J Virol 2005, 79:547-553.

24. Francica JR, Matukonis MK, Bates P: Requirements for cell rounding and surface protein down-regulation by Ebola virus glycoprotein. Virology 2009, 383.237-247.

25. Bartz SR, Vodicka MA: Production of high-titer human immunodeficiency virus type 1 pseudotyped with vesicular stomatitis virus glycoprotein Methods 1997, 12:337-342. 
26. Martin-Serrano J, Perez-Caballero D, Bieniasz PD: Context-dependent effects of $L$ domains and ubiquitination on viral budding. J Virol 2004, 78:5554-5563.

27. Warfield KL, Swenson DL, Olinger GG, Kalina WV, Aman MJ, Bavari S: Ebola virus-like particle-based vaccine protects nonhuman primates against lethal Ebola virus challenge. J Infect Dis 2007, 196(Suppl 2):S430-437.

28. Bhattacharyya S, Warfield KL, Ruthel G, Bavari S, Aman MJ, Hope TJ: Ebola virus uses clathrin-mediated endocytosis as an entry pathway. Virology 2010, 401:18-28.

29. Panchal RG, Ruthel G, Kenny TA, Kallstrom GH, Lane D, Badie SS, Li L, Bavari S, Aman MJ: In vivo oligomerization and raft localization of Ebola virus protein VP40 during vesicular budding. Proc Natl Acad Sci USA 2003, 100:15936-15941.

30. Licata JM, Simpson-Holley M, Wright NT, Han Z, Paragas J, Harty RN: Overlapping motifs (PTAP and PPEY) within the Ebola virus VP40 protein function independently as late budding domains: involvement of host proteins TSG101 and VPS-4. J Virol 2003, 77:1812-1819.

31. McCarthy SE, Johnson RF, Zhang YA, Sunyer JO, Harty RN: Role for amino acids 212KLR214 of Ebola virus VP40 in assembly and budding. J Virol 2007, 81:11452-11460.

32. Kopito RR: Aggresomes, inclusion bodies and protein aggregation. Trends Cell Biol 2000, 10:524-530.

33. Kolesnikova L, Muhlberger E, Ryabchikova E, Becker S: Ultrastructural organization of recombinant Marburg virus nucleoprotein: comparison with Marburg virus inclusions. J Virol 2000, 74:3899-3904.

34. Becker S, Rinne C, Hofsass U, Klenk HD, Muhlberger E: Interactions of Marburg virus nucleocapsid proteins. Virology 1998, 249:406-417.

35. Heath CM, Windsor M, Wileman T: Aggresomes resemble sites specialized for virus assembly. J Cell Biol 2001, 153:449-455.

36. Nozawa N, Yamauchi Y, Ohtsuka K, Kawaguchi Y, Nishiyama Y: Formation of aggresome-like structures in herpes simplex virus type 2-infected cells and a potential role in virus assembly. Exp Cell Res 2004, 299:486-497.

37. Han Z, Harty RN: Packaging of actin into Ebola virus VLPs. Virol J 2005, 2:92.

38. Feldmann H, Kiley MP: Classification, structure, and replication of filoviruses. Curr Top Microbiol Immunol 1999, 235:1-21.

39. Martinez O, Valmas C, Basler CF: Ebola virus-like particle-induced activation of NF-kappaB and Erk signaling in human dendritic cells requires the glycoprotein mucin domain. Virology 2007, 364:342-354

40. Zampieri CA, Fortin JF, Nolan GP, Nabel GJ: The ERK mitogen-activated protein kinase pathway contributes to Ebola virus glycoprotein-induced cytotoxicity. J Virol 2007, 81:1230-1240.

41. Tang QH, Zhang YM, Fan L, Tong G, He L, Dai C: Classic swine fever virus NS2 protein leads to the induction of cell cycle arrest at S-phase and endoplasmic reticulum stress. Virol I 2010, 7:4.

42. Minakshi R, Padhan K, Rani M, Khan N, Ahmad F, Jameel S: The SARS Coronavirus 3 a protein causes endoplasmic reticulum stress and induces ligand-independent downregulation of the type 1 interferon receptor. PLoS One 2009, 4:e8342.

43. Kobayashi T, Beuchat MH, Lindsay M, Frias S, Palmiter RD, Sakuraba H, Parton $\mathrm{RG}$, Gruenberg J: Late endosomal membranes rich in lysobisphosphatidic acid regulate cholesterol transport. Nat Cell Biol 1999, 1:113-118.

doi:10.1186/1743-422X-8-11

Cite this article as: Bhattacharyya and Hope: Full-length Ebola glycoprotein accumulates in the endoplasmic reticulum. Virology Journal $20118: 11$

\section{Submit your next manuscript to BioMed Central and take full advantage of:}

- Convenient online submission

- Thorough peer review

- No space constraints or color figure charges

- Immediate publication on acceptance

- Inclusion in PubMed, CAS, Scopus and Google Scholar

- Research which is freely available for redistribution 